\title{
Parietal Lobes in Schizophrenia: Do They Matter?
}

\author{
Murat Yildiz, ${ }^{1}$ Stefan J. Borgwardt, ${ }^{2}$ and Gregor E. Berger ${ }^{3}$ \\ ${ }^{1}$ Department of Neurology, Cantonal Hospital St. Gallen, 9007 St. Gallen, Switzerland \\ ${ }^{2}$ Psychiatric Outpatient Clinic, University Hospital Basel, 4031 Basel, Switzerland \\ ${ }^{3}$ Integrierte Psychiatrie Winterthur, Zurich Unterland, 8408 Winterthur, Switzerland \\ Correspondence should be addressed to Murat Yildiz, yildizmur@yahoo.com
}

Received 7 June 2011; Revised 28 July 2011; Accepted 10 August 2011

Academic Editor: Hugo Schnack

Copyright () 2011 Murat Yildiz et al. This is an open access article distributed under the Creative Commons Attribution License, which permits unrestricted use, distribution, and reproduction in any medium, provided the original work is properly cited.

\begin{abstract}
Objective. Despite observations that abnormal parietal lobe (PL) function is associated with psychotic-like experiences, our knowledge about the nature of PL involvement in schizophrenia is modest. The objective of this paper is to investigate the role of the PL in schizophrenia. Method. Medline databases were searched for English language publications using the following key words: parietal lobe, combined with schizophrenia, lesions, epilepsy, cognition, rare genetic disorders, MRI, fMRI, PET, and SPECT, respectively, followed by cross-checking of references. Results. Imaging studies in childhood onset schizophrenia suggest that grey matter abnormalities start in parietal and occipital lobes and proceed to frontal regions. Although, the findings are inconsistent, several studies with patients at risk to develop schizophrenia indicate early changes in the PL. Conclusions. We want to propose that in a proportion of individuals with emerging schizophrenia structural and functional alterations may start in the PL and progress to frontal regions.
\end{abstract}

\section{Introduction}

Despite observations that abnormal PL function is associated with psychotic-like experiences, our knowledge about the nature of PL involvement in schizophrenia (SZ) is relatively modest [1]. The PL is engaged in various neuropsychological functions which are affected in schizophrenic patients [2]. The PL supports the frontal lobe in storage and retrieval of verbal information [3]. Episodic memory encoding depends not only on recruiting prefrontal and medial temporal lobes but also on the activation of PL subregions [4]. The right inferior and medial parietal cortices have been associated with the ability to remember past events and arrange them in the right chronological order, consequently enabling us to conceive actions as controlled by ourselves and not a third person [5]. Finally, substantial processing for spatial perception, attention, and self-awareness takes place in the parietal lobes [6-8].

The PL forms strong anatomical connections with the frontal lobe [9]. Frontoparietal white matter maturation correlates with an increase in grey matter activity in both lobes during performance of a working memory (WM) task indicating the close functional connection [10]. Both lobes are frequently activated together while performing cognitive tasks [11]. Joint activation is characterised by a partially symmetrical anteroposterior ordering of activations in both lobes [12]. Croizé et al. demonstrated that although the frontoparietal network is activated in working memory (WM) tasks, both lobes perform distinctive processes [13].

First, we examine the neuropsychiatric manifestations of PL lesions, following a review of selected studies investigating the PL's contribution to SZ. The reevaluation of recent findings allows us to better understand the scope of the PL's influence in SZ. Finally, we propose a new disease model for SZ. A speculative hypothesis will be discussed suggesting that the timing and location of PL changes may differentiate one major pathway in the emergence and progression of SZ.

\section{Method}

Medline databases were searched for English language publications dating from 1966 to February 2011 using the following key words: parietal lobe combined with each of the following key words: schizophrenia, lesions, epilepsy, cognition, rare genetic disorders, MRI, fMRI, PET, and SPECT. 
Cross-checking of references led to the identification of additional relevant references.

2.1. The Anatomical Structure. The parietal lobe can be divided into 3 subregions: the postcentral gyrus, the superior parietal gyrus, and the inferior parietal lobule, consisting of two distinct areas: the angular gyrus and the supramarginal gyrus. The postcentral sulcus separates the postcentral gyrus from the superior parietal gyrus and the inferior parietal lobule. The posteromedial part of the parietal lobe is called the precuneus. The boundaries of the medial surface of the parietal lobe are the frontal, occipital lobes, and the cingulate gyrus. The central sulcus separates the frontal from the parietal lobe. The parieto-occipital fissure lies between the parietal and occipital lobes, and the subparietal sulcus lies between the parietal lobe and cingulate gyrus. From the temporal lobe, the parietal lobe is separated anteriorly by the Sylvian fissure [37].

\subsection{Parietal Lobe Lesions and Their Neuropsychiatric Manifestations}

2.2.1. Stroke and Other Vascular Conditions. Lesions in the PL offer a unique opportunity to identify the consequences of altered PL function (see Table 1). In schizophrenic patients, dysfunctions can be seen which resemble symptoms seen in patients with PL lesions. Right PL injuries are often resulting in abnormal behaviour such as anosognosia [65]. This condition is associated with the denial of any impairment in the face of a hemiparetic limb [66, 67]. Unawareness of disease, lack of insight, is a phenomenon frequently seen in schizophrenic patients $[68,69]$. Unawareness in SZ might occur in connection with deficits of executive functions [70] and thus be very similar to the concept of anosognosia in patients with detectable damage in the PL [71]. An association between structural damage in the frontal lobe and poor insight into illness could be established in schizophrenics [72]. The role of the PL in the phenomenon of unawareness in SZ has yet to be investigated in more detail in the context of the frontoparietal network.

A more obscure neuropsychiatric manifestations is alien hand syndrome (AHS) that may occur after damage of the PL as well as in other brain regions such as the frontal lobe or the corpus callosum [73]. The core symptom of AHS is the perceived loss of control over one's own body movements, that is, a limb. Patients suffer from the impression that an external force is responsible for movements of their own limbs; this symptom is seen occasionally in SZ as well [72]. Sporadically, patients with left PL ischemic lesions display ideomotor apraxia [73, 74] and have difficulties differentiating selfgenerated movements from foreign made movements [21]. Similar findings could be reproduced in healthy participants using transcranial magnetic stimulation of the superior parietal lobule [75]. These findings best correspond to passivity phenomena in SZ, which were associated with PL dysfunctions [76]. These patients report alien control of their limbs due to their inability to align the timing of motor actions internally [77].
Lesions in the posterior parietal cortex highlight the role of this region in disengaging attention from the current focus to a new one [78]. A deterioration of the ability to shift attention has been shown by several research groups in SZ [79]. Additionally, patients with PL lesions may experience difficulties to direct attention to the contralateral exterior world probably due to a disconnection of parieto-frontal networks $[15,80]$. A lateralised defect in the control of attention was associated with the severity of symptoms in SZ [81]. Direct comparisons of the performances of schizophrenics and patients with neglect reveal qualitatively similar impairments [82]. Though, in some schizophrenics defects in spatial [83] and temporal perception are not as impressive as neglect seen in patients with PL lesions [84] and may be the reason that it has not attracted much attention so far.

2.2.2. Parietal Lobe Epilepsy. Focal epilepsy affecting the parietal lobe may also present itself with psychotic symptoms. In a retrospective Canadian study of patients with parietal lobe epilepsy, most patients experienced aurae, nearly all being somatosensory. Some patients described disturbances of body image, visual illusions, vertiginous sensations, and aphasia. A few patients expressed complex visual or auditory hallucinations [85]. Parietal lobe epilepsy often cooccurs with temporal lobe epilepsy which is often accompanied with psychotic like experiences. Marsh et al. described that grey matter volume in the temporal lobes and frontoparietal regions was significantly smaller not only in patients with epilepsy and chronic interictal psychosis but also in patients with unilateral temporal lobe epilepsy without chronic psychosis compared with healthy control subjects [86].

\subsubsection{Rare Genetic Disorders with Parietal Involvement. Velo-} cardiofacial (VCF) syndrome is associated with aberrant parietal and frontotemporal white matter tracts. The VCF syndrome is a rare genetic disorder with a prevalence estimated at 1 in 4,000 live births caused by deletion in chromosome 22q11.2 and characterized by cardiac and facial abnormalities. 25\% of VCF cases present SZ-like symptoms [87] and visuospatial cognitive impairments in adulthood associated with posterior parietal abnormalities [88]. In VCF, autism spectrum disorders [79] and obsessive-compulsive disorder [89] occur frequently. Another rare genetic disorder, fragile $\mathrm{X}$ syndrome, is associated with impaired visual motion processing involving primarily the PL [90]. Mental retardation is the hallmark of fragile $\mathrm{X}$ syndrome caused by silencing of the fragile-X mental retardation (fraX) gene [91]. Interestingly, Rivera et al. demonstrated that the parietal region was more active in patients having a higher expression of fraX gene [92].

\subsection{Parietal Lobes in SZ}

2.3.1. Structural Imaging Studies with Parietal Involvement in Childhood-Onset Schizophrenia. Childhood onset schizophrenia (COS) is defined by its younger age of onset compared to its adult equivalent and may be a more homogeneous group [93]. Studies in COS are particularly important as they 
TABLE 1: Studies reporting lesions in parietal lobe.

\begin{tabular}{|c|c|c|c|c|c|}
\hline Investigator & Lesion site & Subjects & $\begin{array}{l}\text { Affected } \\
\text { function/impairment }\end{array}$ & Conclusion & Type of study \\
\hline $\begin{array}{l}\text { Danckert et al. } \\
2002[14]\end{array}$ & Right PL & $\begin{array}{l}1 \text { patient with visual } \\
\text { neglect }\end{array}$ & $\begin{array}{l}\text { Imagined movements did } \\
\text { not show the same } \\
\text { speed-accuracy trade-off } \\
\text { observed for actual } \\
\text { movements }\end{array}$ & $\begin{array}{l}\text { Right parietal lobe may be } \\
\text { important in the generation } \\
\text { of internal models of motor } \\
\text { movements }\end{array}$ & Case report \\
\hline $\begin{array}{l}\text { Doricchi and } \\
\text { Tomaiuolo } 2004 \\
{[15]}\end{array}$ & $\begin{array}{l}\text { Right hemispheric } \\
\text { damage }\end{array}$ & $\begin{array}{l}21 \text { pts with neglect } \\
10 \text { ctrls }\end{array}$ & Neglect & $\begin{array}{l}\text { Maximal overlap in } \\
\text { supramarginal gyrus and } \\
\text { superior longitudinal } \\
\text { fasciculus; decisive role of } \\
\text { parieto-frontal } \\
\text { disconnection in neglect }\end{array}$ & Case series \\
\hline $\begin{array}{l}\text { Haaland et al. } \\
2000[16]\end{array}$ & Left PL & $\begin{array}{l}41 \text { pts with damage in } \\
\text { left hemisphere }\end{array}$ & Ideomotor apraxia & $\begin{array}{l}\text { Regions in the left } \\
\text { hemisphere important for } \\
\text { goal directed movements }\end{array}$ & Case series \\
\hline $\begin{array}{l}\text { Markowitsch et al. } \\
1999 \text { [17] }\end{array}$ & $\begin{array}{l}\text { Left angular gyrus } \\
\text { lesion }\end{array}$ & 1 patient & $\begin{array}{l}\text { Auditory working memory } \\
\text { dysfunction }\end{array}$ & $\begin{array}{l}\text { Calculation tasks were not } \\
\text { affected }\end{array}$ & Case report \\
\hline $\begin{array}{l}\text { Paterson and } \\
\text { Zangwill } 1944 \text { [18] }\end{array}$ & $\begin{array}{l}\text { Penetrating head } \\
\text { wound affecting the } \\
\text { angular gyrus }\end{array}$ & 1 patient & & Neglect & Case report \\
\hline $\begin{array}{l}\text { Rosler et al. } 1997 \\
{[19]}\end{array}$ & $\begin{array}{l}\text { Ischemic lesion in } \\
\text { the territory of the } \\
\text { right middle cerebral } \\
\text { artery }\end{array}$ & $\begin{array}{l}31 \text { pts with right- or } \\
\text { left- sided infarctions } \\
31 \text { ctrls }\end{array}$ & $\begin{array}{l}\text { Facial recognition ability in } \\
\text { pts with right-sided lesions } \\
\text { was lessened compared } \\
\text { with ctrls and with pts with } \\
\text { left-sided infarctions }\end{array}$ & $\begin{array}{l}\text { Graded impairment in } \\
\text { patients with right middle } \\
\text { cerebral artery infarcts }\end{array}$ & $\begin{array}{l}\text { Cross- } \\
\text { sectional } \\
\text { case-control } \\
\text { study }\end{array}$ \\
\hline
\end{tabular}

\begin{tabular}{|c|c|c|c|c|c|}
\hline $\begin{array}{l}\text { Rossetti et al. } \\
2005 \text { [20] }\end{array}$ & $\begin{array}{l}\text { First case: bilateral } \\
\text { parietal damage } \\
\text { Second case: bilateral } \\
\text { posterior parietal } \\
\text { and upper and lateral } \\
\text { occipital } \\
\text { cortico-subcortical } \\
\text { regions bilaterally } \\
\text { through ischemic } \\
\text { stroke }\end{array}$ & 2 pts & $\begin{array}{l}\text { First case: visual } \\
\text { disorientation, } \\
\text { simultanagnosia, and } \\
\text { severe optic ataxia } \\
\text { Second case: bilateral optic } \\
\text { ataxia }\end{array}$ & $\begin{array}{l}\text { Optic ataxia patients are } \\
\text { impaired for immediate } \\
\text { visuomotor processing but } \\
\text { improve when required to } \\
\text { delay before responding. }\end{array}$ & Case series \\
\hline $\begin{array}{l}\text { Sirigu et al. } 1999 \\
{[21]}\end{array}$ & $\begin{array}{l}\text { Left parietal cortex } \\
\text { damage }\end{array}$ & $\begin{array}{l}3 \text { pts with apraxia } \\
6 \text { ctrls with apraxia } \\
2 \text { nonapraxic } \\
\text { neurological ctrs }\end{array}$ & $\begin{array}{l}\text { pts were impaired in } \\
\text { recognition of the viewed } \\
\text { hand as the examiner's } \\
\text { when it performed } \\
\text { movements similar to their } \\
\text { own movement }\end{array}$ & $\begin{array}{l}\text { Parietal cortex is important } \\
\text { for the perception of own } \\
\text { movements as } \\
\text { self-generated }\end{array}$ & $\begin{array}{l}\text { Cross- } \\
\text { sectional }\end{array}$ \\
\hline
\end{tabular}

PL: parietal lobe; pts: patients; ctrls: healthy controls.

are supposed to be more genetically determined than the adult onset form. As seen in the case of very early onset SZ more severe premorbid neurodevelopmental abnormalities, a higher rate of cytogenetic anomalies and familial SZ are observed than in later onset cases [42].

Thompson et al. described that a dynamic wave of grey matter loss occurs, beginning in the PL and proceeding to the temporal and finally to the prefrontal dorsolateral cortices $[94,95]$. The latter findings suggest that the changes in the PL occur early on in the disease. Although serial brain MRI scans in healthy children over a ten-year period revealed a similar pattern of grey-matter loss beginning in the dorsal parietal and primary sensorimotor regions spreading laterally and caudally into temporal cortices and anteriorly into dorsolateral prefrontal areas [32]. The pattern matches the order of grey matter loss seen in COS; however, the extend of loss is larger in COS. Additionally, Kyriakopoulos et al. demonstrated that compared with healthy controls, individuals with adolescent-onset SZ showed fractional anisotropy decrease in parietal regions, in contrast to individuals with adult onset SZ who showed additional fractional anisotropy reductions in frontal and temporal regions [96]. Fractional anisotropy is measured with diffusion tensor imaging and is positively correlated with the degree of neuronal matura-tion and organisation of white matter tracts [97]. These findings support the concept of SZ as a neurodegenerative disease [29]. 


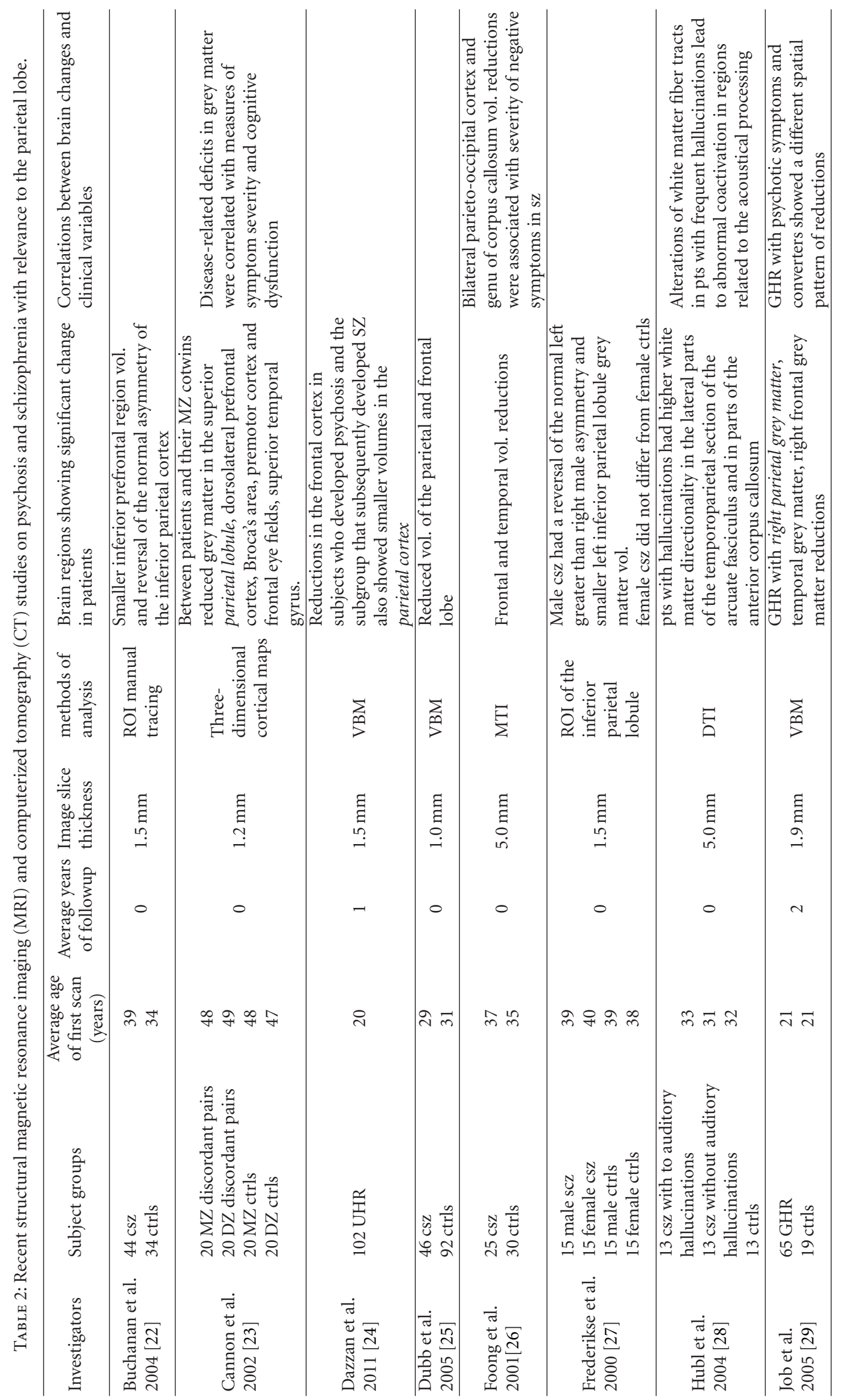




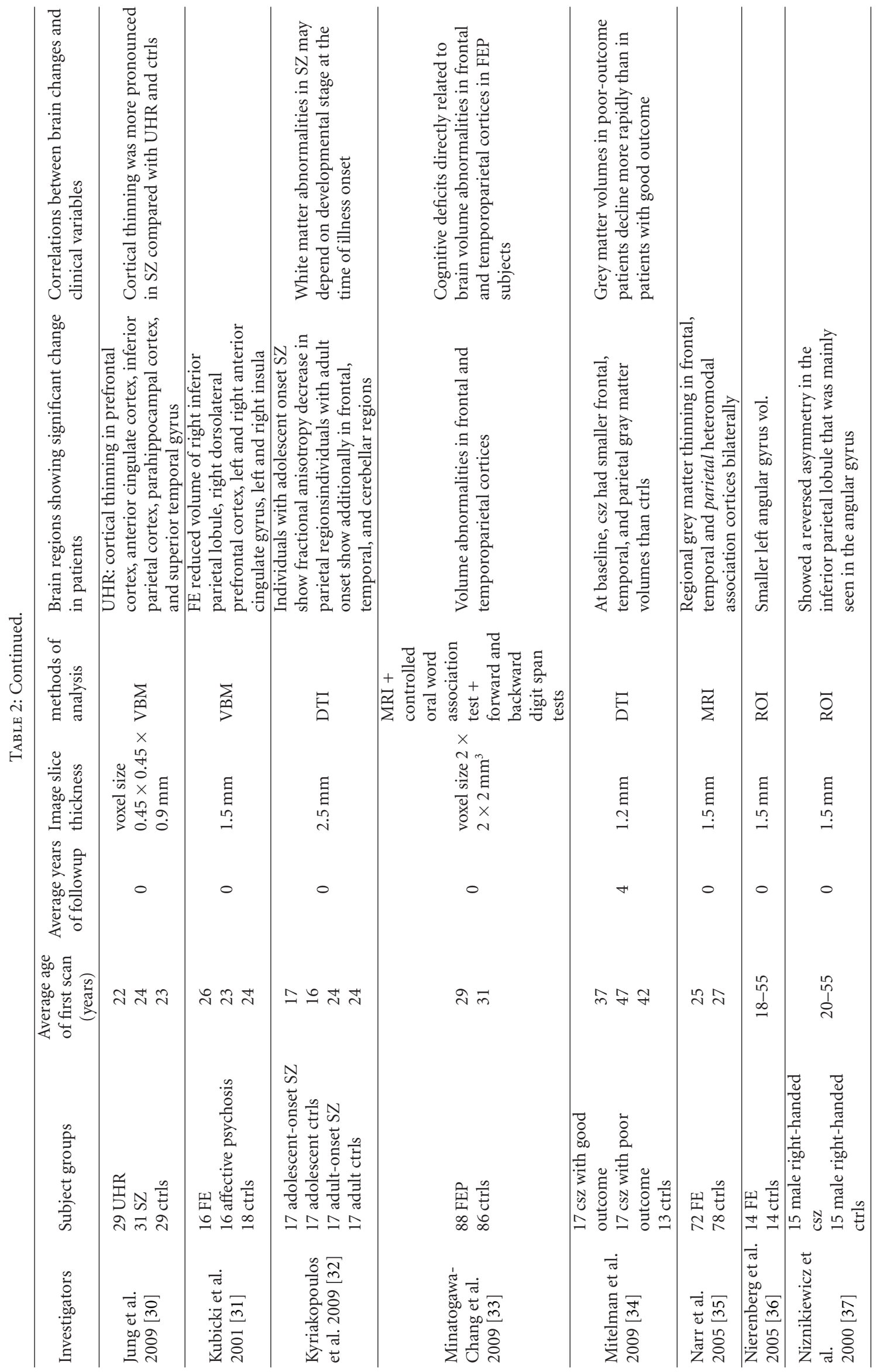




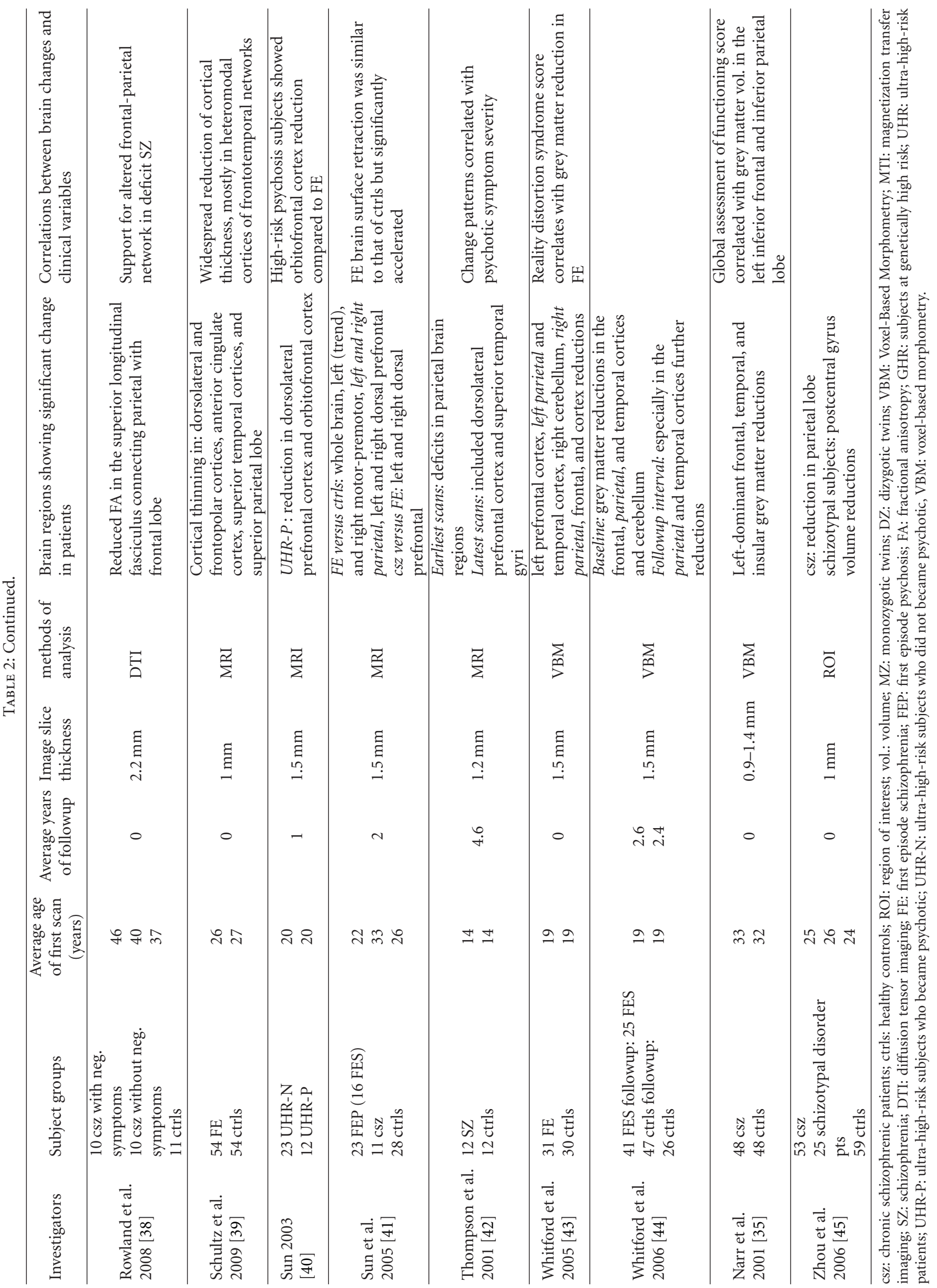




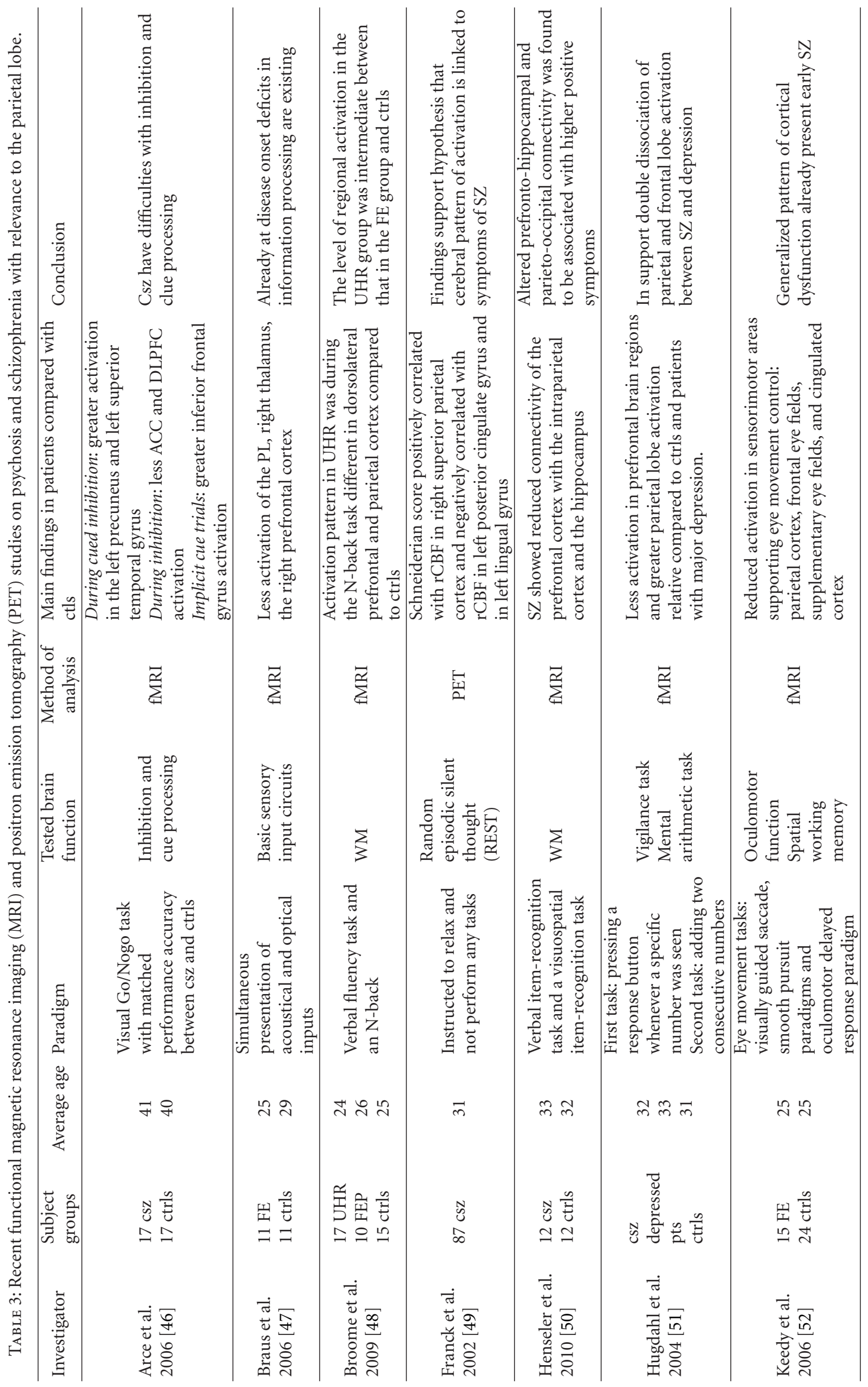




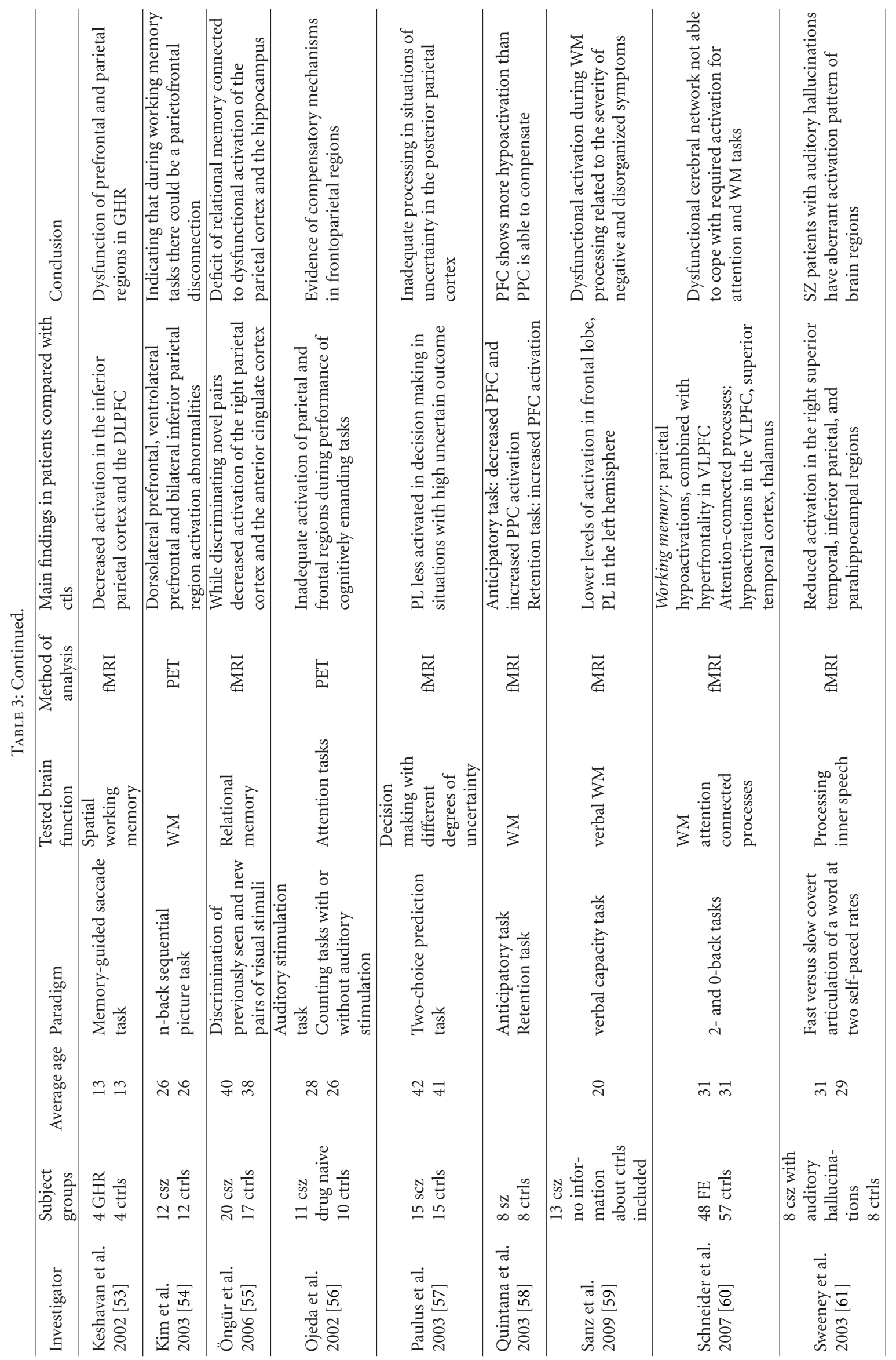




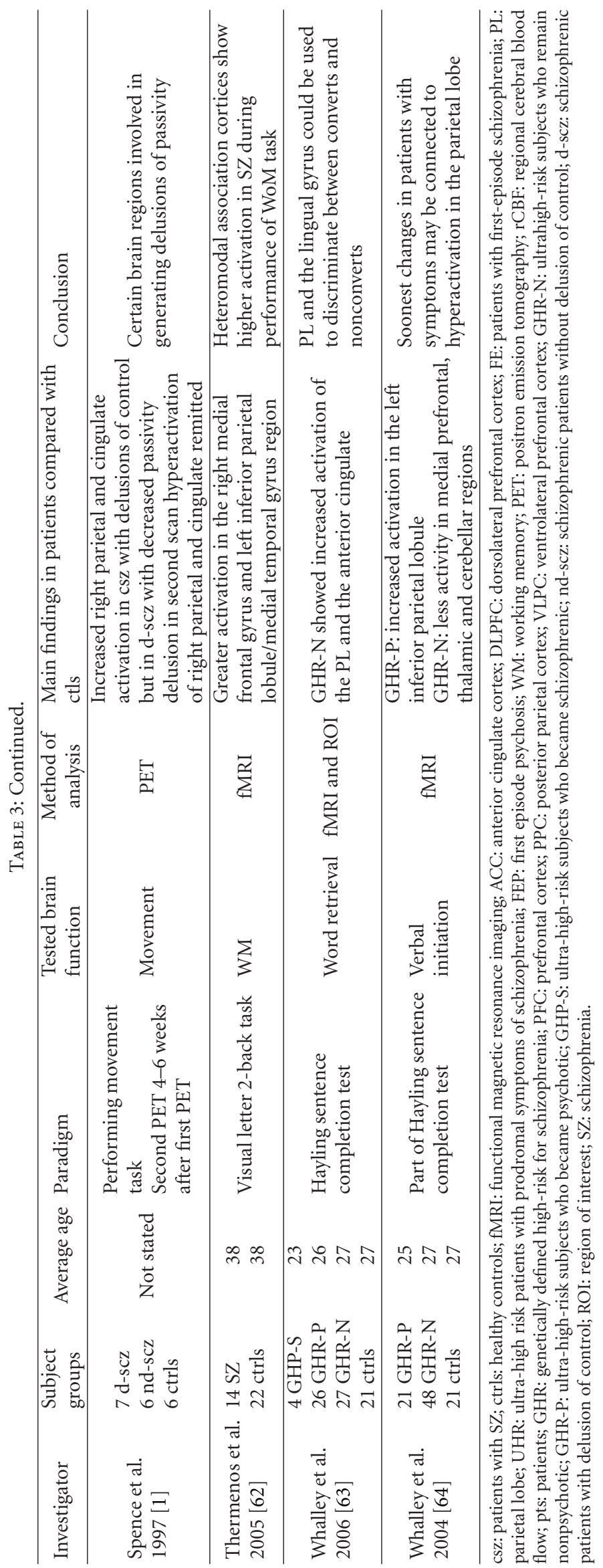


2.3.2. Structural Imaging Studies with Parietal Involvement in High-Risk Patients. In a longitudinal study over two years with a genetically defined high-risk (GHR) cohort from Edinburgh a significant decline in grey matter density was found in the right parietal, right frontal, and temporal lobes [30]. In another study, patients at ultra-high risk (UHR) experiencing prodromal symptoms showed significant cortical thinning in the inferior parietal cortex compared to healthy controls [98]. Borgwardt et al. observed that UHR subjects who later developed psychosis (converters) showed volume reductions in the medial and superior parietal, in the frontal and inferior temporal cortex and in the cerebellum. There were no longitudinal volumetric changes in UHR subjects who did not develop psychosis (nonconverters) [99]. These findings suggest that PL changes may occur prior to the first psychotic episode. However, a previous study from Pantelis et al. could not trace over one year significant changes in the PL of converters. Instead, they demonstrated that converters compared to nonconverters show a longitudinal reduction in the grey matter of the right medial temporal, lateral temporal, inferior frontal, and cingulate cortex bilaterally [39].

2.3.3. Structural Imaging Studies with Parietal Involvement in First-Episode Psychosis and Established Schizophrenia. Reduced cortical thickness in the parietal and frontal regions is already evident in first-episode SZ patients (FE) [40]. It should be noted that a longitudinal surface contraction in frontal and parietal regions of the cortex was found in FE, but not in chronic schizophrenics $[33,100]$. Prefrontal and temporoparietal grey matter volume reductions correlate significantly with cognitive performance in FE, indicating the clinical importance of such alterations [84].

Converging evidence suggests that chronic schizophrenics display PL structural abnormalities (see Table 2). Rowland et al. demonstrated with diffusion tensor imaging (DTI) a de-clined fractional anisotropy of white matter tracts connecting frontal and parietal regions in schizophrenics with negative symptoms [34]. Intriguingly, in the longitudinal four-year followup conducted by Mitelman et al., grey matter volumes in the parietal, frontal, and temporal lobes in schizophrenics with a poor clinical outcome continued to decline more rapidly compared to patients with a good clinical outcome [101]. Using three-dimensional cortical surface maps, a comparison between schizophrenics compared to their unaffect-ed monozygotic cotwins revealed deficits in the superior parietal lobe, dorsolateral prefrontal cortex, and superior temporal gyrus [102]. Additionally, a previous study by the same research group demonstrated that frontal lobe grey matter deficits were present in affected and nonaffected twins [48].

\subsection{Functional Parietal Lobe Abnormalities}

2.4.1. Functional Imaging Studies with Parietal Involvement in at Risk Mental States. Functional MRI (fMRI) studies indicate that UHR individuals display abnormal activation in the prefrontal and parietal cortex during performance of
WM tasks [63]. Whalley et al. reported promising results from a recent longitudinal fMRI study in GHR individuals. fMRI data of converters compared to nonconverters showed increased activation of the PL and decreased activation of the anterior cingulate. However, the PL activation only had high predictive power if the lingual gyrus was also activated [64]. The study was limited as only 4 out of 62 at risk individuals developed SZ. Nevertheless, this study might demonstrate that parietal functional abnormalities are present in high-risk subjects who later become psychotic.

The same study group found in GHR individuals increased connectivity between the left parietal and left prefrontal regions compared to healthy controls. The authors interpreted the hyperactivation of the PL as compensatory, since there were no differences in performance between the groups [64]. These results underline that many PL findings are reported in connection with the frontoparietal network.

2.4.2. Functional Imaging Studies with Parietal Involvement in First-Episode Psychosis and in Chronic Schizophrenia. Prefrontal cortex dysfunctions have been identified as a key factor in SZ [103]. The role of PL dysfunctions still remains ambiguous in SZ. Parietal hypoactivation and ventrolateral prefrontal hyperactivity during WM tasks in FE patients indicate that frontoparietal networks are impaired early in the course of the illness [60]. Correspondingly, in patients with chronic SZ, parietal and frontal cortex activation deficits were described in WM tasks [104]. There is an increasing body of studies associating PL dysfunctions with a variety of symptoms in chronic SZ [105]. For instance, a PET study correlated positively regional cerebral blood flow in right superior parietal cortex with the severity of Schneiderian firstrank symptoms (voices conversing or commenting; thought broadcasting, withdrawal or insertion; made actions and thoughts) [49]. Moreover, Menon et al. demonstrated that thinking disturbance was correlated with deficits in activation in the parietal and the right frontal cortices [104]. In fact, overactivity in the right inferior parietal cortex was associated with the presence of delusions of control in a study with acute psychotic schizophrenics performing movement tasks. Interestingly, the activity in this region returned to normal levels when patients were symptom-free [1]. Lower levels of activation during verbal WM task performance in the left hemisphere across frontal and parietal regions were associated with poorer role functioning and greater severity of negative and disorganised symptoms [59]. A recent study identified disturbed parieto-occipital functional connectivity as related with positive symptoms of SZ [50]. These findings underline that two core symptoms of SZ, cognitive deficits and delusions, may be related to malfunctions in the parietal lobe [106].

\section{Discussion}

The nature of the pathological processes underlying progressive structural and functional changes in SZ and their exact timing in the brains remains unclear. Our paper provides a selection of studies indicating that PL lesions and epilepsy 
may cause psychotic-like symptoms and supports the concept that PL abnormalities could be important for SZ and related disorders. Structural brain irregularities in PL were found in imaging studies in COS suggesting that grey matter abnormalities start in parietal and occipital lobes and proceed in a dynamic wave to frontal cortices $[42,94]$. This illustrates that PL structural alterations may occur early in the course of illness and points to genetic influences, yet to be determined [93]. The contribution of genetic factors to parietal involvement in SZ is further supported by a significant decline in grey matter found over time in GHR subjects [29]. The brain-derived neurotrophic factor (BDNF) could be one of the candidate genes for parietal lobe alterations seen in SZ. Indeed, there was decreased activity in the bilateral posterior parietal regions in GHR patients with BDNF Val homozygote versus BDNF Met carriers [107].

There is evidence that parietal lobe abnormalities may be only partially genetically determined as parietal lobe alterations were seen in monozygotic twins with SZ but not in their nonaffected twins [101]. There are studies indicating parietal structural alterations in the early phase of psychosis [99]. However, a reduction in the parietal volume was not found in the UHR sample from Melbourne [98]. This inconsistency could be explained by major methodological differences of both studies: the study by Borgwardt et al. spanned a time period of 3-4 years and the analysed MRI slices were $1 \mathrm{~mm}$ thick, whereas the Melbourne group observed their sample over 1 year and acquired MRI slices that were $3 \mathrm{~mm}$ thick [98, 99]. In a recent UHR study from Melbourne applying voxel-based morphometry methodology in $1.5 \mathrm{~mm}$ thick MRI slices, reductions in frontal and parietal cortices were detected in the UHR group who later converted to a psychotic disorder compared to those who did not convert [24].

The neurodevelopmental hypothesis suggests that early insults in pregnancy and infancy combined with genetic factors render the brain vulnerable for later development of SZ [108]. However, symptoms usually occur many years after the implied first damage $[100,109]$, hence a second insult was proposed to explain for the long delay [100]. Here, we want to propose that in a proportion of patients subsequently developing SZ, structural and functional alterations may start in parietal lobes progressing to frontal regions. The "parietal type" of SZ development may clinically present initially with working memory deficits $[50,56,58,60]$ and disturbed self-conceptualization $[1,84]$. The "parietal type" may be more relevant for early onset forms of psychotic disorders in adolescents, with COS being the most extreme variant. In this model, genetic influences would play a more prominent role. Additional causative factors, yet to be identified, interacting with brain maturational processes in late adolescence and early adulthood may be decisive in the transition to a full-blown psychotic disorder [110]. Such an approach may enable us to characterise subtypes of SZ based on structural and functional brain processes and not merely on pure phenomenology.

The functional interdependency of the parietal and frontal cortices was revealed in GHR subjects with isolated psychotic symptoms. They displayed compensatory activation in the left inferior parietal lobule while performing the Hayling sentence completion task [40]. Additionally, Quintana et al. reported parietal cortex activation in schizophrenics as compensatory mechanism for prefrontal cortex dysfunction while performing a working memory task [58]. However, Schneider et al. described parietal hypoactivation combined with hyperfrontality in first-episode schizophrenia patients with poorer performance [60]. In contrast to the study by Schneider and colleagues, in the studies conducted by Whalley and Quintana no statistical differences in performance accuracy were found between patients and controls. The hyperactivation of the PL may compensate for frontal hypoactivity, then the network between the frontal and parietal cortices is sufficient; hence tasks can be performed adequately. But in case of a disconnection in the frontoparietal network [50], the PL is not recruited to support the frontal lobe. This could lead to an inadequate hyperactivation of the frontal lobe leading to poor performance. This hypothesis warrants confirmation in carefully planned studies.

Finally, some voxel-based morphometry studies have not found PL volume reductions in FEP $[61,111]$ and chronic SZ $[108,112]$. More research is required to explore parietal lobe functions and volumes across different stages of SZ. Whether the pattern of parietal lobe changes is suitable for identifying a more homogeneous subgroup of patients with emerging SZ remains to be determined. Further longitudinal data are necessary from the earliest stages of SZ, particularly in prepsychotic individuals, to resolve this issue. A better understanding of the time course of structural and functional brain changes across different stages of psychotic disorders [109] will finally help us to distinguish between those individuals at incipient risk for a major mental illness and those with merely a transient crisis in life.

\section{Acknowledgment}

Murat Yildiz has received travel Grants from Merck Serono, Bayer AG, and Biogen Idec.

\section{References}

[1] S. A. Spence, D. J. Brooks, S. R. Hirsch, P. F. Liddle, J. Meehan, and P. M. Grasby, "A PET study of voluntary movement in schizophrenic patients experiencing passivity phenomena (delusions of alien control)," Brain, vol. 120, no. 11, pp. 1997-2011, 1997.

[2] E. Antonova, T. Sharma, R. Morris, and V. Kumari, "The relationship between brain structure and neurocognition in schizophrenia: a selective review," Schizophrenia Research, vol. 70, no. 2-3, pp. 117-145, 2004.

[3] J. Jonides, E. H. Schumacher, E. E. Smith et al., "The role of parietal cortex in verbal working memory," Journal of Neuroscience, vol. 18, no. 13, pp. 5026-5034, 1998.

[4] A. E. Cavanna and M. R. Trimble, "The precuneus: a review of its functional anatomy and behavioural correlates," Brain, vol. 129, no. 3, pp. 564-583, 2006.

[5] K. Vogeley, R. Tepest, T. Schneider-Axmann et al., "Automated image analysis of disturbed cytoarchitecture in Brodmann area 10 in schizophrenia," Schizophrenia Research, vol. 62, no. 1-2, pp. 133-140, 2003. 
[6] M. F. S. Rushworth, A. Ellison, and V. Walsh, "Complementary localization and lateralization of orienting and motor attention," Nature Neuroscience, vol. 4, no. 6, pp. 656-661, 2001.

[7] D. Thoenissen, K. Zilles, and I. Toni, "Differential involvement of parietal and precentral regions in movement preparation and motor intention," Journal of Neuroscience, vol. 22, no. 20, pp. 9024-9034, 2002.

[8] J. Gottlieb, "From thought to action: the parietal cortex as a bridge between perception, action, and cognition," Neuron, vol. 53, no. 1, pp. 9-16, 2007.

[9] B. Seltzer and D. N. Pandya, "Further observations on parieto-temporal connections in the rhesus monkey," Experimental Brain Research, vol. 55, no. 2, pp. 301-312, 1984.

[10] P. J. Olesen, Z. Nagy, H. Westerberg, and T. Klingberg, "Combined analysis of DTI and fMRI data reveals a joint maturation of white and grey matter in a fronto-parietal network," Cognitive Brain Research, vol. 18, no. 1, pp. 48-57, 2003.

[11] J. M. Gurd, K. Amunts, P. H. Weiss et al., "Posterior parietal cortex is implicated in continuous switching between verbal fluency tasks: an fMRI study with clinical implications," Brain, vol. 125, no. 5, pp. 1024-1038, 2002.

[12] O. Simon, F. Kherif, G. Flandin et al., "Automatized clustering and functional geometry of human parietofrontal networks for language, space, and number," NeuroImage, vol. 23, no. 3, pp. 1192-1202, 2004.

[13] A. C. Croizé, R. Ragot, L. Garnero et al., "Dynamics of parietofrontal networks underlying visuospatial short-term memory encoding," NeuroImage, vol. 23, no. 3, pp. 787-799, 2004.

[14] J. Danckert, S. Ferber, T. Doherty, H. Steinmetz, D. Nicolle, and M. A. Goodale, "Selective, non-lateralized impairment of motor imagery following right parietal damage," Neurocase, vol. 8, no. 3, pp. 194-204, 2002.

[15] F. Doricchi and F. Tomaiuolo, "The anatomy of neglect without hemianopia: a key role for parietal-frontal disconnection?" NeuroReport, vol. 14, no. 2, pp. 239-243, 2003.

[16] K. Y. Haaland, D. L. Harrington, and R. T. Knight, "Neural representations of skilled movement," Brain, vol. 123, no. 11, pp. 2306-2313, 2000.

[17] H. J. Markowitsch, E. Kalbe, J. Kessler, H. M. Von Stockhausen, M. Ghaemi, and W. D. Heiss, "Short-term memory deficit after focal parietal damage," Journal of Clinical and Experimental Neuropsychology, vol. 21, no. 6, pp. 784-797, 1999.

[18] A. Paterson and O. L. Zangwill, "Disorders of visual space perception associated with lesions of the right cerebral hemisphere," Brain, vol. 67, no. 4, pp. 331-358, 1944.

[19] A. Rosler, S. Lanquillon, and O. Dippel, "Impairment of facial recognition in patients with right cerebral infarcts quantified by computer aided morphing," Journal of Neurology, Neurosurgery \& Psychiatry, vol. 62, pp. 261-264, 1997.

[20] Y. Rossetti, P. Revol, R. McIntosh et al., "Visually guided reaching: bilateral posterior parietal lesions cause a switch from fast visuomotor to slow cognitive control," Neuropsychologia, vol. 43, no. 2, pp. 162-177, 2005.

[21] A. Sirigu, E. Daprati, P. Pradat-Diehl, N. Franck, and M. Jeannerod, "Perception of self-generated movement following left parietal lesion," Brain, vol. 122, no. 10, pp. 1867-1874, 1999.

[22] R. W. Buchanan, A. Francis, C. Arango et al., "Morphometric assessment of the heteromodal association cortex in Schizophrenia," American Journal of Psychiatry, vol. 161, no. 2, pp. 322-331, 2004.
[23] T. D. Cannon, P. M. Thompson, T. G. M. Van Erp et al., "Cortex mapping reveals regionally specific patterns of genetic and disease-specific gray-matter deficits in twins discordant for schizophrenia," Proceedings of the National Academy of Sciences of the United States of America, vol. 99, no. 5, pp. 3228-3233, 2002.

[24] P. Dazzan, B. Soulsby, A. Mechelli et al., "Volumetric abnormalities predating the onset of schizophrenia and affective psychoses: an MRI study in subjects at ultrahigh risk of psychosis," Schizophrenia Bulletin. In press.

[25] A. Dubb, Z. Xie, R. Gur, R. Gur, and J. Gee, "Characterization of brain plasticity in schizophrenia using template deformation," Academic Radiology, vol. 12, no. 1, pp. 3-9, 2005.

[26] J. Foong, M. R. Symms, G. J. Barker et al., "Neuropathological abnormalities in schizophrenia: evidence from magnetization transfer imaging," Brain, vol. 124, no. 5, pp. 882-892, 2001.

[27] M. Frederikse, A. Lu, E. Aylward, P. Barta, T. Sharma, and G. Pearlson, "Sex differences in inferior parietal lobule volume in schizophrenia," American Journal of Psychiatry, vol. 157, no. 3, pp. 422-427, 2000.

[28] D. Hubl, T. Koenig, W. Strik et al., "Pathways that make voices: white matter changes in auditory hallucinations," Archives of General Psychiatry, vol. 61, no. 7, pp. 658-668, 2004.

[29] D. E. Job, H. C. Whalley, E. C. Johnstone, and S. M. Lawrie, "Grey matter changes over time in high risk subjects developing schizophrenia," NeuroImage, vol. 25, no. 4, pp. 10231030, 2005.

[30] W. H. Jung, J. S. Kim, J. H. Jang et al., "Cortical thickness reduction in individuals at ultra-high-risk for psychosis," Schizophrenia Bulletin, vol. 37, no. 4, pp. 839-849, 2011.

[31] M. Kubicki, M. E. Shenton, D. F. Salisbury et al., "Voxel-based morphometric analysis of gray matter in first episode schizophrenia," NeuroImage, vol. 17, no. 4, pp. 1711-1719, 2002.

[32] M. Kyriakopoulos, R. Perez-Iglesias, J. B. Woolley et al., "Effect of age at onset of schizophrenia on white matter abnormalities," British Journal of Psychiatry, vol. 195, no. 4, pp. 346-353, 2009.

[33] T. M. Minatogawa-Chang, M. S. Schaufelberger, A. M. Ayres et al., "Cognitive performance is related to cortical grey matter volumes in early stages of schizophrenia: a population-based study of first-episode psychosis," Schizophrenia Research, vol. 113, no. 2-3, pp. 200-209, 2009.

[34] S. A. Mitelman, E. L. Canfield, R. E. Newmark et al., "Longitudinal assessment of gray and white matter in chronic schizophrenia: a combined diffusion-tensor and structural magnetic resonance imaging study," The Open Neuroimaging Journal, vol. 3, pp. 31-47, 2009.

[35] K. L. Narr, R. M. Bilder, A. W. Toga et al., "Mapping cortical thickness and gray matter concentration in first episode schizophrenia," Cerebral Cortex, vol. 15, no. 6, pp. 708-719, 2005.

[36] J. Nierenberg, D. F. Salisbury, J. J. Levitt, E. A. David, R. W. McCarley, and M. E. Shenton, "Reduced left angular gyrus volume in first-episode schizophrenia," American Journal of Psychiatry, vol. 162, no. 8, pp. 1539-1541, 2005.

[37] M. Niznikiewicz, R. Donnino, R. W. McCarley et al., "Abnormal angular gyrus asymmetry in schizophrenia," American Journal of Psychiatry, vol. 157, no. 3, pp. 428-437, 2000.

[38] L. M. Rowland, E. A. Spieker, A. Francis, P. B. Barker, W. T. Carpenter, and R. W. Buchanan, "White matter alterations in deficit schizophrenia," Neuropsychopharmacology, vol. 34, no. 6, pp. 1514-1522, 2009. 
[39] C. C. Schultz, K. Koch, G. Wagner et al., "Reduced cortical thickness in first episode schizophrenia," Schizophrenia Research, vol. 116, no. 2-3, pp. 204-209, 2010.

[40] D. Sun, G. W. Stuart, S. J. Wood et al., "Progressive frontal lobe reduction in first episode psychosis," Schizophrenia Research, vol. 60, p. 208, 2003.

[41] D.-Q. Sun, Longitudinal brain changes in early psychosis: a magnetic resonance imaging study, Ph.D. dissertation, University of Melbourne, 2005.

[42] P. M. Thompson, C. Vidal, J. N. Giedd et al., "Mapping adolescent brain change reveals dynamic wave of accelerated gray matter loss in very early-onset schizophrenia," Proceedings of the National Academy of Sciences of the United States of America, vol. 98, no. 20, pp. 11650-11655, 2001.

[43] T. J. Whitford, T. F. D. Farrow, L. Gomes, J. Brennan, A. W. F. Harris, and L. M. Williams, "Grey matter deficits and symptom profile in first episode schizophrenia," Psychiatry Research, vol. 139, no. 3, pp. 229-238, 2005.

[44] T. J. Whitford, S. M. Grieve, T. F. D. Farrow et al., "Progressive grey matter atrophy over the first 2-3 years of illness in firstepisode schizophrenia: a tensor-based morphometry study," NeuroImage, vol. 32, no. 2, pp. 511-519, 2006.

[45] S. Y. Zhou, M. Suzuki, T. Takahashi et al., "Parietal lobe volume deficits in schizophrenia spectrum disorders," Schizophrenia Research, vol. 89, no. 1-3, pp. 35-48, 2007.

[46] E. Arce, D. S. Leland, D. A. Miller, A. N. Simmons, K. C. Winternheimer, and M. P. Paulus, "Individuals with schizophrenia present hypo- and hyperactivation during implicit cueing in an inhibitory task," NeuroImage, vol. 32, no. 2, pp. 704-713, 2006.

[47] D. F. Braus, W. Weber-Fahr, H. Tost, M. Ruf, and F. A. Henn, "Sensory information processing in neuroleptic-naive firstepisode schizophrenic patients: a functional magnetic resonance imaging study," Archives of General Psychiatry, vol. 59, no. 8, pp. 696-701, 2002.

[48] M. R. Broome, P. Matthiasson, P. Fusar-Poli et al., "Neural correlates of executive function and working memory in the 'at-risk mental state', British Journal of Psychiatry, vol. 194, no. 1, pp. 25-33, 2009.

[49] N. Franck, D. S. O'Leary, M. Flaum, R. D. Hichwa, and N. C. Andreasen, "Cerebral blood flow changes associated with Schneiderian first-rank symptoms in Schizophrenia," Journal of Neuropsychiatry and Clinical Neurosciences, vol. 14, no. 3, pp. 277-282, 2002.

[50] I. Henseler, P. Falkai, and O. Gruber, "Disturbed functional connectivity within brain networks subserving domainspecific subcomponents of working memory in schizophrenia: relation to performance and clinical symptoms," Journal of Psychiatric Research, vol. 44, no. 6, pp. 364-372, 2010.

[51] K. Hugdahl, B. R. Rund, A. Lund et al., "Brain activation measured with fMRI during a mental arithmetic task in Schizophrenia and major depression," American Journal of Psychiatry, vol. 161, no. 2, pp. 286-293, 2004.

[52] S. K. Keedy, C. L. Ebens, M. S. Keshavan, and J. A. Sweeney, "Functional magnetic resonance imaging studies of eye movements in first episode schizophrenia: smooth pur-suit, visually guided saccades and the oculomotor delayed response task," Psychiatry Research, vol. 146, no. 3, pp. 199-211, 2006.

[53] M. S. Keshavan, V. A. Diwadkar, S. M. Spencer, K. A. Harenski, B. Luna, and J. A. Sweeney, "A preliminary functional magnetic resonance imaging study in offspring of schizophrenic parents," Progress in Neuro-Psychopharmacology and Biological Psychiatry, vol. 26, no. 6, pp. 1143-1149, 2002.
[54] J. J. Kim, J. S. Kwon, J. P. Hae et al., "Functional disconnection between the prefrontal and parietal cortices during working memory processing in schizophrenia: a $[15(\mathrm{O})] \mathrm{H} 2 \mathrm{O}$ PET study," American Journal of Psychiatry, vol. 160, no. 5, pp. 919-923, 2003.

[55] D. Öngür, T. J. Cullen, D. H. Wolf et al., "The neural basis of relational memory deficits in schizophrenia," Archives of General Psychiatry, vol. 63, no. 4, pp. 356-365, 2006.

[56] N. Ojeda, F. Ortuno, J. Arbizu et al., "Functional neuroanatomy of sustained attention in schizophrenia: contribution of parietal cortices," Human Brain Mapping, vol. 17, pp. 116-130, 2002.

[57] M. P. Paulus, L. Frank, G. G. Brown, and D. L. Braff, "Schizophrenia subjects show intact success-related neural activation but impaired uncertainty processing during decision-making," Neuropsychopharmacology, vol. 28, no. 4, pp. 795-806, 2003.

[58] J. Quintana, T. Wong, E. Ortiz-Portillo et al., "Prefrontalposterior parietal networks in schizophrenia: primary dysfunctions and secondary compensations," Biological Psychiatry, vol. 53, no. 1, pp. 12-24, 2003.

[59] J. H. Sanz, K. H. Karlsgodt, C. E. Bearden et al., "Symptomatic and functional correlates of regional brain physiology during working memory processing in patients with recent onset schizophrenia," Psychiatry Research, vol. 173, no. 3, pp. 177-182, 2009.

[60] F. Schneider, U. Habel, M. Reske et al., "Neural correlates of working memory dysfunction in first-episode schizophrenia patients: an fMRI multi-center study," Schizophrenia Research, vol. 89, no. 1-3, pp. 198-210, 2007.

[61] J. A. Sweeney, T. Li, Q. Gong et al., "Association of cerebral deficits with clinical symptoms in antipsychotic-naive firstepisode schizophrenia: an optimized voxel-based morphometry and resting state functional connectivity study," American Journal of Psychiatry, vol. 166, no. 2, pp. 196-205, 2009.

[62] H. W. Thermenos, J. M. Goldstein, S. L. Buka et al., "The effect of working memory performance on functional MRI in schizophrenia," Schizophrenia Research, vol. 74, no. 2-3, pp. 179-194, 2005.

[63] H. C. Whalley, E. Simonotto, W. Moorhead et al., "Functional imaging as a predictor of schizophrenia," Biological Psychiatry, vol. 60, no. 5, pp. 454-462, 2006.

[64] H. C. Whalley, E. Simonotto, S. Flett et al., "fMRI correlates of state and trait effects in subjects at genetically enhanced risk of schizophrenia," Brain, vol. 127, no. 3, pp. 478-490, 2004.

[65] G. Berlucchi and S. Aglioti, "The body in the brain: neural bases of corporeal awareness," Trends in Neurosciences, vol. 20, no. 12, pp. 560-564, 1997.

[66] J. W. Cooney and M. S. Gazzaniga, "Neurological disorders and the structure of human consciousness," Trends in Cognitive Sciences, vol. 7, no. 4, pp. 161-165, 2003.

[67] V. S. Ramachandran, D. Rogers-Ramachandran, and S. Cobb, "Touching the phantom limb," Nature, vol. 377, no. 6549, pp. 489-490, 1995.

[68] E. Kraepelin, Dementia Praecox, Churchill Livingston, New York, NY, USA, 1919.

[69] X. F. Amador and J. M. Gorman, "Psychopathologic domains and insight in schizophrenia," Psychiatric Clinics of North America, vol. 21, no. 1, pp. 27-42, 1998.

[70] S. Sevy, K. Nathanson, H. Visweswaraiah, and X. Amador, "The relationship between insight and symptoms in schizophrenia," Comprehensive Psychiatry, vol. 45, no. 1, pp. 16-19, 2004. 
[71] L. Pia and M. Tamietto, "Unawareness in schizophrenia: neuropsychological and neuroanatomical findings," Psychiatry and Clinical Neurosciences, vol. 60, no. 5, pp. 531-537, 2006.

[72] M. U. Shad, S. Muddasani, K. Prasad, J. A. Sweeney, and M. S. Keshavan, "Insight and prefrontal cortex in first-episode Schizophrenia," NeuroImage, vol. 22, no. 3, pp. 1315-1320, 2004.

[73] M. A. Kikkert, G. M. Ribbers, and P. J. Koudstaal, "Alien hand syndrome in stroke: a report of 2 cases and review of the literature," Archives of Physical Medicine and Rehabilitation, vol. 87, no. 5, pp. 728-732, 2006.

[74] L. J. Buxbaum, S. H. Johnson-Frey, and M. Bartlett-Williams, "Deficient internal models for planning hand-object interactions in apraxia," Neuropsychologia, vol. 43, no. 6, pp. 917929, 2005.

[75] P. A. MacDonald and T. Paus, "The role of parietal cortex in awareness of self-generated movements: a transcranial magnetic stimulation study," Cerebral Cortex, vol. 13, no. 9, pp. 962-967, 2003.

[76] J. Danckert, M. Saoud, and P. Maruff, "Attention, motor control and motor imagery in schizophrenia: implications for the role of the parietal cortex," Schizophrenia Research, vol. 70, no. 2-3, pp. 241-261, 2004.

[77] P. Maruff, P. Wilson, and J. Currie, "Abnormalities of motor imagery associated with somatic passivity phenomena in schizophrenia," Schizophrenia Research, vol. 60, no. 2-3, pp. 229-238, 2003.

[78] M. I. Posner, J. A. Walker, F. J. Friedrich, and R. D. Rafal, "Effects of parietal injury on covert orienting of attention," Journal of Neuroscience, vol. 4, no. 7, pp. 1863-1874, 1984.

[79] S. Jazbec, C. Pantelis, T. Robbins, T. Weickert, D. R. Weinberger, and T. E. Goldberg, "Intra-dimensional/extra-dimensional set-shifting performance in schizophrenia: impact of distractors," Schizophrenia Research, vol. 89, no. 1-3, pp. 339349, 2007.

[80] G. Vallar, "Extrapersonal visual unilateral spatial neglect and its neuroanatomy," NeuroImage, vol. 14, no. 1, pp. S52-S58, 2001.

[81] S. A. Harvey, E. Nelson, J. W. Haller, and T. S. Early, "Lateralization attentional abnormality in schizophrenia is correlated with severity of symptoms," Biological Psychiatry, vol. 33, no. 2, pp. 93-99, 1993.

[82] C. Cavézian, Y. Rossetti, J. Danckert, T. d'Amato, J. Dalery, and M. Saoud, "Exaggerated leftward bias in the mental number line of patients with schizophrenia," Brain and Cognition, vol. 63, no. 1, pp. 85-90, 2007.

[83] C. Cavézian, J. Danckert, J. Lerond, J. Daléry, T. d'Amato, and M. Saoud, "Visual-perceptual abilities in healthy controls, depressed patients, and schizophrenia patients," Brain and Cognition, vol. 64, no. 3, pp. 257-264, 2007.

[84] C. Cavezian, C. Striemer, M. Saoud, Y. Rossetti, and J. Danckert, "Schizophrenia and the neglect syndrome: parietal contributions to cognitive dysfunction in schizophrenia," Current Psychiatry Reviews, vol. 2, no. 4, pp. 439-451, 2006.

[85] V. Salanova, F. Andermann, T. Rasmussen, A. Olivier, and L. F. Quesney, "Parietal lobe epilepsy. Clinical manifestations and outcome in 82 patients treated surgically between 1929 and 1988," Brain, vol. 118, no. 3, pp. 607-627, 1995.

[86] L. Marsh, E. V. Sullivan, M. Morrell, K. O. Lim, and A. Pfefferbaum, "Structural brain abnormalities in patients with schizophrenia, epilepsy, and epilepsy with chronic interictal psychosis," Psychiatry Research, vol. 108, no. 1, pp. 1-15, 2001.
[87] N. Barnea-Goraly, V. Menon, B. Krasnow, A. Ko, A. Reiss, and S. Eliez, "Investigation of white matter structure in velocardiofacial syndrome: a diffusion tensor imaging study," American Journal of Psychiatry, vol. 160, no. 10, pp. 1863-1869, 2003.

[88] J. Burn and J. Goodship, "Developmental genetics of the heart," Current Opinion in Genetics and Development, vol. 6, no. 3, pp. 322-325, 1996.

[89] C. S. Kogan, A. Bertone, K. Cornish et al., "Integrative cortical dysfunction and pervasive motion perception deficit in fragile X syndrome," Neurology, vol. 63, no. 9, pp. 1634-1639, 2004.

[90] G. Turner, T. Webb, S. Wake, and H. Robinson, "Prevalence of fragile X syndrome," American Journal of Medical Genetics, vol. 64, no. 1, pp. 196-197, 1996.

[91] S. M. Rivera, V. Menon, C. D. White, B. Glaser, and A. L. Reiss, "Functional brain activation during arithmetic processing in females with fragile $\mathrm{X}$ syndrome is related to FMRI protein expression," Human Brain Mapping, vol. 16, no. 4, pp. 206-218, 2002.

[92] B. Childs and C. R. Scriver, "Age at onset and causes of disease," Perspectives in Biology and Medicine, vol. 29, no. 3, pp. 437-460, 1986.

[93] R. Nicolson and J. L. Rapoport, "Childhood-onset schizophrenia: rare but worth studying," Biological Psychiatry, vol. 46, no. 10, pp. 1418-1428, 1999.

[94] A. W. Toga, P. M. Thompson, and E. R. Sowell, "Mapping brain maturation," Trends in Neurosciences, vol. 29, no. 3, pp. 148-159, 2006.

[95] N. Gogtay, A. Sporn, L. S. Clasen et al., "Structural brain MRI abnormalities in healthy siblings of patients with childhoodonset schizophrenia," American Journal of Psychiatry, vol. 160, no. 3, pp. 569-571, 2003.

[96] C. Beaulieu, "The basis of anisotropic water diffusion in the nervous system - a technical review," NMR in Biomedicine, vol. 15, no. 7-8, pp. 435-455, 2002.

[97] I. Feinberg, "Schizophrenia: caused by a fault in programmed synaptic elimination during adolescence?" Journal of Psychiatric Research, vol. 17, no. 4, pp. 319-334, 1982.

[98] C. Pantelis, M. Yücel, S. J. Wood, P. D. McGorry, and D. Velakoulis, "Early and late neurodevelopmental disturbances in schizophrenia and their functional consequences," Australian and New Zealand Journal of Psychiatry, vol. 37, no. 4, pp. 399-406, 2003.

[99] S. J. Borgwardt, P. K. McGuire, J. Aston et al., "Reductions in frontal, temporal and parietal volume associated with the onset of psychosis," Schizophrenia Research, vol. 106, no. 2-3, pp. 108-114, 2008.

[100] C. Pantelis, M. Yücel, S. J. Wood et al., "Structural brain imaging evidence for multiple pathological processes at different stages of brain development in schizophrenia," Schizophrenia Bulletin, vol. 31, no. 3, pp. 672-696, 2005.

[101] S. J. Borgwardt, M. M. Picchioni, U. Ettinger, T. Toulopoulou, R. Murray, and P. K. McGuire, "Regional gray matter volume in monozygotic twins concordant and discordant for schizophrenia," Biological Psychiatry, vol. 67, no. 10, pp. 956964, 2010.

[102] T. D. Cannon, M. O. Huttunen, J. Lonnqvist et al., "The inheritance of neuropsychological dysfunction in twins discordant for schizophrenia," American Journal of Human Genetics, vol. 67, no. 2, pp. 369-382, 2000.

[103] D. R. Weinberger, "Prefrontal function in schizophrenia: confounds and controversies," Philosophical Transactions of the Royal Society B, vol. 351, no. 1346, pp. 1495-1503, 1996. 
[104] V. Menon, R. T. Anagnoson, D. H. Mathalon, G. H. Glover, and A. Pfefferbaum, "Functional neuroanatomy of auditory working memory in schizophrenia: relation to positive and negative symptoms," NeuroImage, vol. 13, no. 3, pp. 433-446, 2001.

[105] A. P. Weiss, C. B. Ellis, J. L. Roffman et al., "Aberrant frontoparietal function during recognition memory in schizophrenia: a multimodal neuroimaging investigation," Journal of Neuroscience, vol. 29, no. 36, pp. 11347-11359, 2009.

[106] G. D. Pearlson, R. G. Petty, C. A. Ross, and A. Y. Tien, "Schizophrenia: a disease of heteromodal association cortex?" Neuropsychopharmacology, vol. 14, no. 1, pp. 1-17, 1996.

[107] B. J. Baig, H. C. Whalley, J. Hall et al., "Functional magnetic resonance imaging of BDNF val66met polymorphism in unmedicated subjects at high genetic risk of schizophrenia performing a verbal memory task," Psychiatry Research, vol. 183, no. 3, pp. 195-201, 2010.

[108] J. M. Segall, J. A. Turner, T. G. M. Van Erp et al., "Voxelbased morphometric multisite collaborative study on schizophrenia," Schizophrenia Bulletin, vol. 35, no. 1, pp. 82-95, 2009.

[109] P. D. McGorry, I. B. Hickie, A. R. Yung, C. Pantelis, and H. J. Jackson, "Clinical staging of psychiatric disorders: a heuristic framework for choosing earlier, safer and more effective interventions," Australian and New Zealand Journal of Psychiatry, vol. 40, no. 8, pp. 616-622, 2006.

[110] H. Sakata, M. Taira, M. Kusunoki, A. Murata, and Y. Tanaka, "The TINS lecture: the parietal association cortex in depth perception and visual control of hand action," Trends in Neurosciences, vol. 20, no. 8, pp. 350-357, 1997.

[111] A. K. Malla, M. Bodnar, R. Joober, and M. Lepage, "Duration of untreated psychosis is associated with orbital-frontal grey matter volume reductions in first episode psychosis," Schizophrenia Research, vol. 125, no. 1, pp. 13-20, 2011.

[112] W. Y. Chan, M. Y. Chia, G. L. Yang et al., "Duration of illness, regional brain morphology and neurocognitive correlates in schizophrenia," Annals of the Academy of Medicine Singapore, vol. 38, no. 5, pp. 388-395, 2009. 


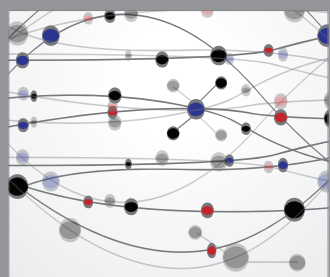

The Scientific World Journal
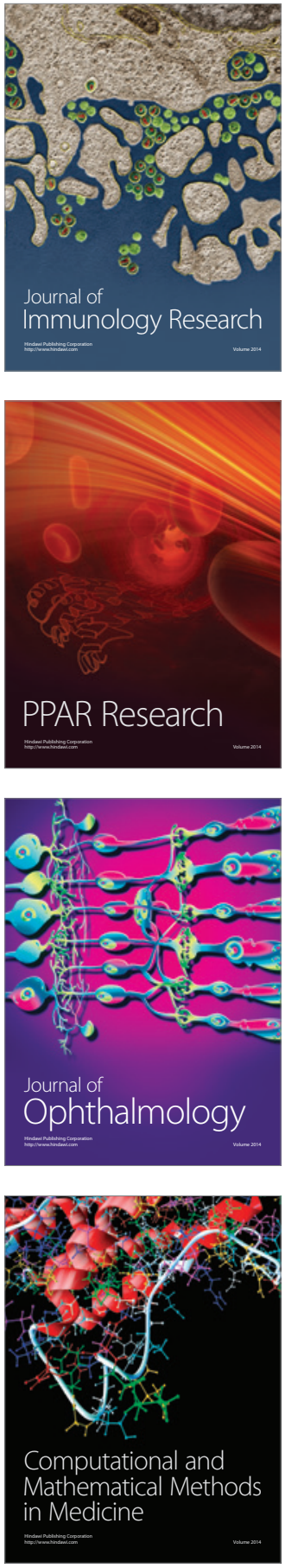



Gastroenterology

Research and Practice


\section{Hindawi}

Submit your manuscripts at

http://www.hindawi.com
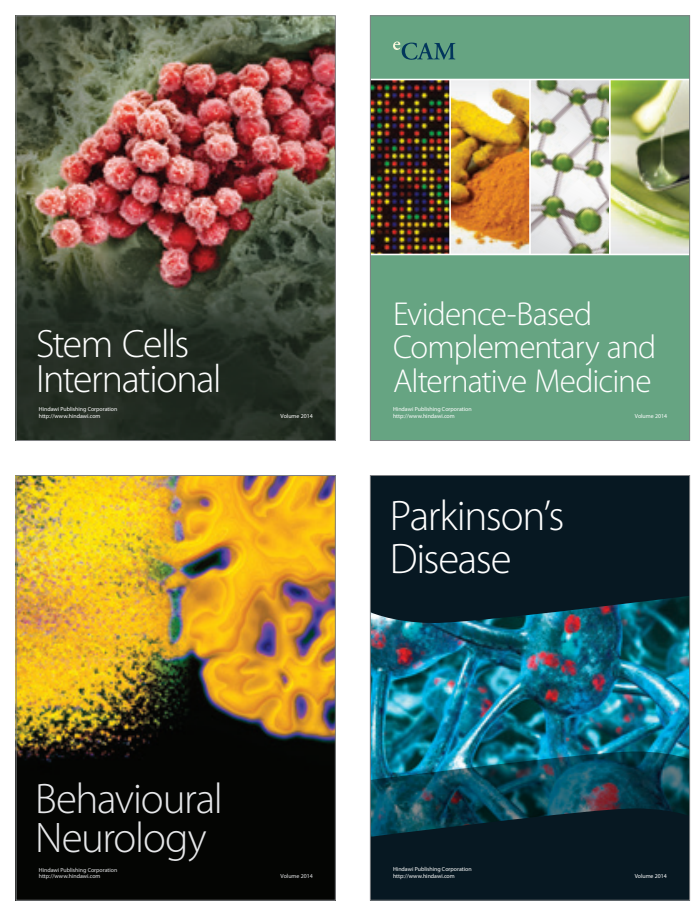

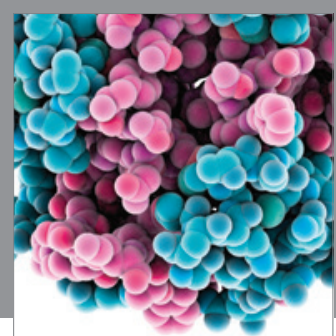

Journal of
Diabetes Research

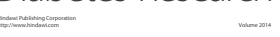

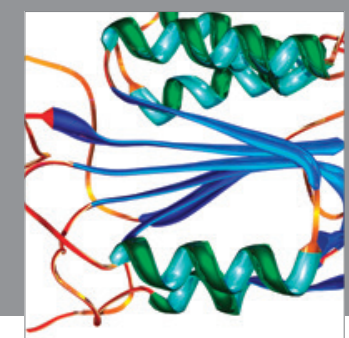

Disease Markers
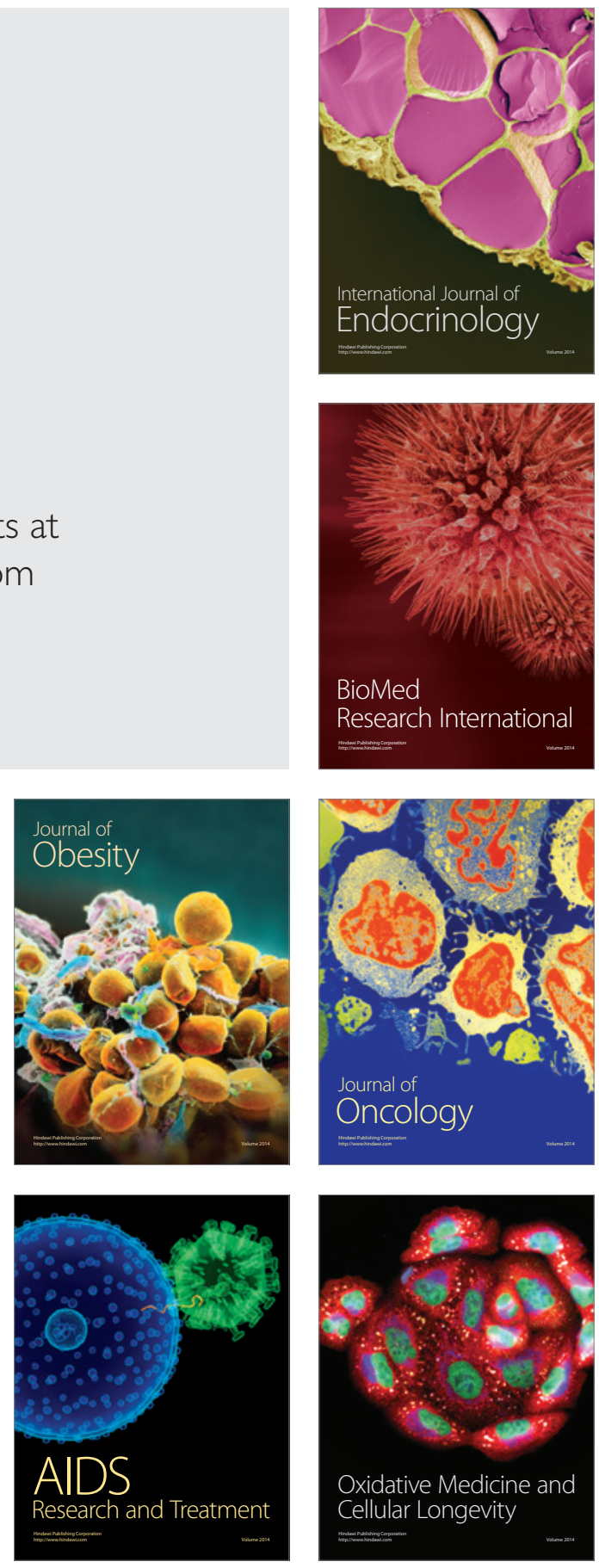